\title{
EARLY SURGICAL COMPLICATIONS OF TOTAL HIP ARTHROPLASTY RELATED TO SURGICAL APPROACH
}

\author{
Wayne Hoskins, MBBS (Hons), FRACS, PhD 1,2,3 \\ Michelle M Dowsey, $\mathrm{PhD}^{3,4}$ \\ Tim Spelman, MBBS, $\mathrm{PhD}^{5}$ \\ Peter FM Choong, MBBS, MD, FRACS, FAOrthA ${ }^{3,4}$
}

1. Faculty of Medicine, Dentistry and Health Sciences

The University of Melbourne

Parkville, Victoria Australia

2. Traumaplasty.Melbourne

East Melbourne, Victoria Australia

3. Department of Orthopaedics

St. Vincent's Hospital

Fitzroy, Victoria Australia

4. The University of Melbourne Department of Surgery

St. Vincent’s Hospital

Victoria Australia

5. Macfarlane Burnet Centre for Medical Research

Centre for Epidemiology \& Population Research

Melbourne, Victoria Australia

This is the author manuscript accepted for publication and has undergone full peer review but has not been through the copyediting, typesetting, pagination and proofreading process, which may lead to differences between this version and the Version of Record. Please cite this article as doi: $10.1111 /$ ans.16149

This article is protected by copyright. All rights reserved. 
Please address all correspondence to:

Name: Wayne Hoskins

Address: Gipps Street Consulting Suites, St Francis Building, Suite 12 Level 1, 166

Gipps St East Melbourne VIC 3002 Australia

Phone: +61 399286786

Fax: +61 390787335

Email: wayne.hoskins@outlook.com 


\section{Abstract}

\section{Background}

Total hip arthroplasty (THA) can be performed through a number of surgical approaches. The aim was to compare the incidence of early surgical complications in THA related to approach.

\section{$\underline{\text { Methods }}$}

A retrospective review of prospectively recorded data extracted from St. Vincent’s Melbourne Arthroplasty Registry was performed between January 2006 and December 2016. Surgical approach was identified: lateral, posterior, anterior and superior. Primary outcome measure was return to theatre (RTT) for any cause within one year. Age, comorbidity, BMI and femoral fixation were assessed for potential confounding. Secondary outcomes were RTT for revision procedure and for specific complications: intra or post-operative fracture, dislocation/instability, aseptic loosening and prosthetic joint injection (PJI). Variables were assessed for their association with outcome using unadjusted and adjusted quantile median regression for continuous outcomes and Cox proportional hazards regression for binary timeto-event outcomes.

\section{$\underline{\text { Results }}$}

There were a total of 2906 consecutive THA’s recorded, 1413 lateral, 1188 posterior, 233 anterior and 72 superior. 140 cases (4.5\%) required RTT within one year. No approach was 
associated with RTT on unadjusted analyses or multivariate modelling. There was no association between approach and revision, PJI, or periprosthetic fracture. The posterior approach was associated with 2.90 times the rate of dislocation relative to the lateral $(\mathrm{p}=0.005)$.

\section{Conclusions}

There was no difference in the RTT rate between surgical approaches for THA. There was no difference in revision rates, PJI or periprosthetic fracture. The posterior approach was associated with a higher rate of dislocation relative to the lateral, but not the anterior.

Key words: Total hip replacement; hip prosthesis; osteoarthritis; hip; orthopedics 


\section{Background}

Total hip arthroplasty (THA) has proven to be a reliable and durable surgical procedure affording patient improvement in pain and function. ${ }^{1}$ Despite good outcomes, surgeons have attempted to improve the results of THA through the usage of different surgical approaches. The most common approaches traditionally have been the lateral (or Hardinge) and posterior approaches. ${ }^{2}$ More recently, the anterior and superior approaches (SuperPath) have been introduced. ${ }^{3,4}$ Surgical innovation should occur in a way that improves outcomes whilst minimising surgical and medical complications. ${ }^{5}$

Each surgical approach has its theoretical benefits to the patient and surgeon, along with potential disadvantages and unique complications. The lateral approach has the advantage of good exposure of the acetabulum and femur, joint stability ${ }^{6,7}$ through preservation of the posterior capsule, but suffers from gluteal dysfunction ${ }^{8}$ and post-operative limp. ${ }^{2}$ The posterior approach overcomes the disadvantages of the trans-gluteal lateral approach, ${ }^{8}$ provides excellent exposure to the femur and acetabulum but suffers from a risk of instability through posterior capsulotomy and detachment of the short external rotators ${ }^{6,7,9}$. The risk of instability has been partly mitigated through the advent of larger heads. ${ }^{10}$ The anterior approach theoretically has a lower risk of instability ${ }^{6,7}$ through preserving the posterior capsule and early improvements in function through its inter-nervous, inter-muscular approach, ${ }^{11}$ but is limited with its femoral exposure resulting in a higher rate of femoral sided complications. ${ }^{6,12,13}$ The superior approach in theory has the potential advantages of stability and faster post-operative recovery preserving abductor and capsular attachments, but may be 
hampered by its limited exposure, difficulty with component positioning and a likely learning curve with a newer technique. Long term data is yet to indicate a specific approach to have a significant advantage over another with regards to revision rates, ${ }^{9}$ or a subset of patients that may benefit from a particular approach. There is some controversy as to whether surgical complications differ between approaches. ${ }^{14-16}$

\begin{abstract}
Although International registries have reported on surgical approach, ${ }^{6,8,9,17}$ they have largely focused on revision procedures rather than other complications that may necessitate return to theatre, which tend to be underreported. It is only with large volume, long term, multisurgeon in-depth data collection that the complications and benefits of each THA approach can be determined and compared. The primary aim of the study was to compare the incidence of early THA complications requiring return to theatre related to surgical approach occurring at a single hospital. The secondary aim was to compare complications that required revision procedure and specific complications.
\end{abstract}

\title{
Methods
}

St. Vincent's Hospital is a high-volume arthroplasty centre based in Melbourne, Australia. A prospectively recorded database, the St. Vincent’s Melbourne Arthroplasty (SMART) Registry has been established to record outcomes including complications following THA. A retrospective cohort study was performed using data extracted from the SMART registry. Inclusion criteria were all patients who underwent a primary elective THA at St. Vincent's Hospital between $1^{\text {st }}$ January 2006 and $31^{\text {st }}$ December 2016. All surgical approaches were 
identified: lateral, posterior, anterior and superior. The primary outcome measure of the study was return to theatre for any cause within one year related to surgical approach. The secondary outcome measures were return to theatre for revision procedure and specific complications within one year: intra or post-operative fracture, dislocation/instability, aseptic loosening and prosthetic joint infection (PJI). Predictor variables such as age, gender, smoking status, American Society of Anesthesiologists (ASA) Score, Charlson Comorbidity Index (CCI), body mass index (BMI), head diameter and method of femoral fixation were assessed for potential confounding. All data required for this study is contained within the SMART Registry for which ethics approval has been obtained (HREC-A 100/14). This specific study also received ethical approval (QA 066 / 17).

\section{$\underline{\text { Statistical analysis }}$}

Data from the SMART Registry was de-identified prior to analysis. Baseline characteristics between the four approach groups were compared using a one-way ANOVA, Kruskal-Wallis test or a chi-square tests as appropriate. The exposure and a priori selected predictor variables were assessed for their association with the outcome using unadjusted and adjusted quantile median regression for continuous outcomes and Cox proportional hazards regression for binary time-to-event outcomes. Multivariate analyses were performed for each outcome of interest. Each model included surgical approach as the predictor of interest, with the lateral approach used as the reference. Models were adjusted for any covariate associated with the outcome on univariate analyses at the level of $p<0.1$. Year of surgery was also included in each model. All statistical analyses were performed using Stata Version 14.0. 


\section{Results}

There were a total of 2906 THA’s recorded, 1413 lateral (48.6\%), 1188 posterior (40.9\%), 233 anterior (8.0\%) and 72 superior (2.5\%). The patients in the lateral and posterior groups were slightly older and with more females than the superior group, with patient characteristics presented in Table 1. The lateral approach was performed or supervised by 15 consultant surgeons, posterior 20, anterior 6 and superior 3 . There was a total of 130 primary outcomes of complications that required return to theatre within one year (4.5\%). Relative to the lateral approach, neither the posterior, anterior or superior approaches were associated with return to theatre on unadjusted analyses (Table 2). There was no statistical difference made between age at surgery $(\mathrm{p}=0.391)$, gender $(\mathrm{p}=0.427)$, smoking status $(\mathrm{p}=0.586)$, ASA $(p=0.165)$, CCI $(p=0.080)$, hybrid fixation $(p=0.085)$ or cemented fixation $(p=0.056)$. Every additional year later of procedure was associated with a $6 \%$ reduction in the rate of unplanned procedure (Hazard Ration $(\mathrm{HR})=0.94$ (0.89 to 0.99$), \mathrm{p}=0.040)$. Morbidly obese patients (BMI 240) were associated with 3.14 times the rate of an unplanned procedure relative to normal weight (HR 3.14; 95\% CI 1.63-6.07). Increasing head size diameter was associated with progressively larger reductions in unplanned procedure rate with the $32 \mathrm{~mm}$ and $\geq 36 \mathrm{~mm}$ heads associated with 33\% (HR 0.67; 95\% CI 0.46-0.97) and 43\% (HR 0.57; 95\% CI 0.340.97 ) reductions respectively relative to $\leq 28 \mathrm{~mm}$ heads.

Multivariable modelling using all predictors with $\mathrm{p}<0.1$ on univariable modelling found no association between surgical approach and unplanned procedures. 
In terms of the secondary outcome measures, there were 46 cases that had a revision procedure (1.6\%) within one year. There was no association between approach and revision procedure and the other secondary outcomes of PJI or periprosthetic fracture (Table 3). The posterior approach was associated with 2.90 times the rate of dislocation relative to the lateral approach $(\mathrm{p}=0.005)$. There was no difference between the posterior and anterior approach for dislocation. There were insufficient cases to analyse aseptic loosening for all approaches (lateral $n=1$, posterior $n=2$, anterior and superior $n=0$ ).

\section{Discussion}

The aim of this study was to compare the incidence of early return to theatre and surgical complications in THA related to surgical approach occurring at a single hospital. The overall return to theatre rate was $4.5 \%$ within one year and there was no difference in the overall return to theatre rate between surgical approaches. The overall revision rate was $1.6 \%$ at one year and there was no difference between surgical approaches. There was no difference between surgical approaches for the secondary outcome measures of PJI and periprosthetic fracture. The posterior approach had a higher dislocation risk when compared with the lateral approach, but not the anterior.

There has been controversy as to the preferred surgical approach for THA. Many of the published results for surgical approaches including comparative data have come from single surgeon case series. ${ }^{18-21}$ Less literature has come from International Joint Registries, ${ }^{6,8,9,17}$ or multi-surgeon populations ${ }^{7}$ such as this study, which better reflects population-based 
practice. Joint registries can be limited in that most only record revision procedures and they do not record or report on other complications, particularly those that may not require return to theatre, or those that did require a return to theatre but without a revision procedure. These tend to be underreported and our study showed an approximate three times higher risk of complications that required return to theatre rather than revision procedure within one year. The results of this study suggest that each of the three main surgical approaches are safe with regards to early return to theatre and revision. This is supported by data from the Australian Orthopaedic Association National Joint Replacement Registry (AOANJRR) and the Norwegian Registry showing no difference in implant survival between approaches, ${ }^{9,17}$ as well as recent meta-analyses that have found no difference in complications between the different approaches ${ }^{14-16}$ In contrast, the Dutch registry has found a lower revision rate with the posterior approach when compared with other approaches, ${ }^{6}$ whilst the AOANJRR found a different complication profile between approaches with more femoral sided complications requiring revision procedure with the anterior approach: more fractures and aseptic loosening but less PJI and dislocation. ${ }^{17}$

As demonstrated in this study and others, anterior THA can be successfully performed, ${ }^{18-20}$ but is not without complications. ${ }^{21-24}$ Concerns with THA utilising the anterior approach have been with femoral sided complications, ${ }^{12,13,17,25,26}$ including subsidence, ${ }^{27}$ and fracture; ${ }^{17,26,28-}$ 32 resulting in early femoral stem revision. ${ }^{25,26,31}$ The Swedish and Dutch Registries and the AOANJRR have shown this to be a cause of a higher revision rate. ${ }^{6,9,17}$ We focused on complications occurring in the short term and it may be that with long term follow up a 
difference may be evident. Although anterior approach THA can be technically demanding, with difficult exposure and femoral access, requiring longer surgical time, ${ }^{27,32,33}$ and greater blood loss, ${ }^{33}$ our study showed that this may not result in an overall higher complication rate in the short term. In contrast, data from a large Australian private hospital comparing 949 anterior THA, 870 posterior and 618 lateral THA, found the anterior approach to have more periprosthetic fractures treated with internal fixation at the time of the index procedure, and also a higher rate of revisions for periprosthetic fracture in the first 30 days $^{34}$. Complications have been shown to relate to surgeon experience and learning curve, ${ }^{35}$ and potentially implant choice. ${ }^{36}$ The results of our study may have been positive for the anterior approach given that many of the surgeons performing anterior THA had completed their learning curve and we have adjusted for year of surgery. Likewise, potentially more difficult cases may have been chosen to be performed through the more traditional lateral and posterior approaches and we cannot exclude the possibility of selection bias in the results or assess the decision-making process of individual surgeons. The anterior approach was only used for $8.0 \%$ of cases and complications may have been higher had the approach been used more often. Furthermore, other complications that did not require return to theatre such as lateral femoral cutaneous nerve palsy were not recorded and may have proven to be significant given the association of this injury with the anterior approach. ${ }^{27,37}$

The major criticism of the posterior approach has been the increased risk of dislocation and revision for instability. In this study, we found dislocation to be higher following the posterior approach when compared to the lateral, but not other approaches. This is supported 
by data from the Dutch ${ }^{6}$ and Norwegian Registry which found an approximate doubling of risk for dislocation with the posterior approach when compared with the lateral approach. ${ }^{9}$ Similar results were found in the AOANJRR with a higher rate of dislocation with the posterior approach compared to the lateral and anterior approaches. ${ }^{17}$ Likewise, the Kaiser Permanente Registry found the anterior and lateral approaches to have a lower risk of dislocation when compared with the posterior approach (1.4\% vs. 0.8\%), although there were no differences in adjusted risk of revision. ${ }^{7}$ However, not every study has found an increased dislocation rate with the posterior approach, including the English and Wales Registry. ${ }^{8}$ Our study is not the first to demonstrate a lack of difference for dislocation between the posterior and anterior approaches, ${ }^{9,21,27,29}$ with state wide registry data of $11,112^{, 38}$ and $>2100$ cases in another series ${ }^{31}$ having the same finding. When performing posterior THA, strategies should be put in place to minimise the risk of dislocation. As this study showed, increasing the head diameter is one such strategy, as other authors have found. ${ }^{10}$

There are limitations with the study. Being a public teaching hospital, many of the THAs were performed by orthopaedic surgeons in training at varying levels of experience and it is not recorded to what extent each procedure was performed by them, or with what degree of supervision by the primary surgeon, each with varying degrees of training and experience. However, a study performed at this institution showed no increase in complication rate by trainee surgeons. ${ }^{39}$ Likewise, we did not account for a particular surgeon's complication profile. As the data was collected over an extensive period of time, there may be a likelihood of complications decreasing with time due to secular trends. To account for this we adjusted 
for year of surgery and found there to be no difference with year of surgery. However, there was no superior approach performed prior to 2013 and no anterior approach performed prior to 2008. As they are newer techniques, they may have more favourable outcomes being performed by senior surgeons, alternatively they suffer from a learning curve which could produce worse outcomes. The superior and anterior approaches were both performed by fewer surgeons and have fewer numbers than the lateral and posterior approaches. Also recognizing that some surgeons do more than one approach and therefore there is a risk of selection bias. We acknowledge that the newer introduction of these approaches and lower number of patients and surgeons is a limitation of the study. Also, we did not review the specifics of each case to assess the degree of complexity which may have influenced surgical decision making for approach and also the risk of complication. As with any registry, multiple factors can influence outcome and we attempted to minimize this by accounting for confounding in our analyses. Further, the complication rate in this study may be different to other published series due to a unit policy of solely performing cemented femoral stem THA in patients aged $>65$, which has been shown to reduce fracture rate with the anterior approach. ${ }^{28}$ This study focused on short term complications and it may be that differences between approaches become evident with longer term follow up and with larger number of cases. Despite the robust active surveillance program of the SMART registry whereby all patients are contacted at the one-year mark to survey for pain and function and check for complications, we cannot entirely rule out that we have not captured every complication that may have been treated outside the hospital and not captured in the database. Lastly, we chose our primary outcome measure to be return to theatre and our secondary outcome measures to 
be revision procedure and specific complications. We did not include medical complications, which may have been different between approaches.

\section{Conclusions}

No difference in overall return to theatre rates at one year were identified between surgical approaches for THA. There was no difference in revision rates, PJI or periprosthetic fracture, although the posterior approach was associated with a higher rate of dislocation relative to the lateral approach, but not the anterior approach. Future study should identify a patient and surgeon profile best suited to a particular approach and strategies to reduce dislocation through a posterior approach such that the modern hip surgeon can minimize complication rates.

\section{Acknowledgements}

Peter Choong, Michelle Dowsey, and Tim Spelman are recipients of a National Health and Medical Research Council (NHMRC) Centre for Research Excellence Grant in Total Joint Replacement (1116325).

Associate Professor Michelle Dowsey is supported by a NHMRC Career Development Fellowship (APP1122526)

Professor Peter Choong is supported by a NHMRC Practitioner Fellowship (APP1154203)

This article is protected by copyright. All rights reserved. 


\section{References}

1. Learmonth ID, Young C, Rorabeck C. The operation of the century: total hip replacement. Lancet. 2007;370(9597):1508-19.

2. Rosenlund S, Broeng L, Holsgaard-Larsen A, Jensen C, Overgaard S. Patient-reported outcome after total hip arthroplasty: comparison between lateral and posterior approach: A randomized controlled trial in 80 patients with 12-month follow-up. Acta Orthop. 2017;88(3):239-247.

3. Mohan R, Yi PH, Hansen EN. Evaluating online information regarding the direct anterior approach for total hip arthroplasty. J Arthroplasty. 2015;30(5):803-7.

4. Cardenas-Nylander C, Bellotti V, Astarita E, Moya Gomez E, Fernandez MR. Innovative approach in total hip arthroplasty: supercapsular percutaneously-assisted. Hip Int. 2016;26 Suppl 1:34-7.

5. Melvin JS, Karthikeyan T, Cope R, Fehring TK. Early failures in total hip arthroplasty — a changing paradigm. J Arthroplasty. 2014;29(6):1285-8.

6. Zijlstra WP, De Hartog B, Van Steenbergen LN, Scheurs BW, Nelissen RGHH. Effect of femoral head size and surgical approach on risk of revision for dislocation after total hip arthroplasty. Acta Orthop. 2017;88(4):395-401.

7. Sheth D, Cafri G, Inacio MC, Paxton EW, Namba RS. Anterior and Anterolateral Approaches for THA Are Associated With Lower Dislocation Risk Without Higher Revision Risk. Clin Orthop Relat Res. 2015;473(11):3401-8.

8. Jameson SS, Mason J, Baker P, Gregg PJ, McMurtry IA, Deehan DJ, Reed MR. A comparison of surgical approaches for primary hip arthroplasty: a cohort study of 
patient reported outcome measures (PROMs) and early revision using linked national databases. J Arthroplasty. 2014;29(6):1248-1255.e1.

9. Mjaaland KE, Fenstad AM, Havelin LI, Furnes O, Nordsletten L. Implant Survival After Minimally Invasive Anterior or Anterolateral Vs. Conventional Posterior or Direct Lateral Approach: An Analysis of 21,860 Total Hip Arthroplasties from the Norwegian Arthroplasty Register (2008 to 2013). J Bone Joint Surg Am. 2017;99(10):840-847.

10. Berry DJ, von Knoch M, Schleck CD, Harmsen WS. Effect of femoral head diameter and operative approach on risk of dislocation after primary total hip arthroplasty. $\mathrm{J}$ Bone Joint Surg Am. 2005;87:2456-63.

11. Malek IA, Royce G, Bhatti SU, Whittaker JP, Phillips SP, Wilson IR, Wootton JR, Starks I. A comparison between the direct anterior and posterior approaches for total hip arthroplasty: the role of an 'Enhanced Recovery' pathway. Bone Joint J. 2016;98-B(6):754-60.

12. Eto S, Hwang K, Huddleston JI, Amanatullah DF, Maloney WJ, Goodman SB. The Direct Anterior Approach is Associated With Early Revision Total Hip Arthroplasty. J Arthroplasty. 2017;32(3):1001-1005.

13. Hoskins WT, Bingham RJ, Lorimer M, de Steiger RN. The Effect of Size for a Hydroxyapatite-Coated Cementless Implant on Component Revision in Total Hip Arthroplasty: An Analysis of 41,265 Stems. J Arthroplasty. 2020;35(4):1074-1078

14. Miller LE, Gondusky JS, Bhattacharyya S Kamath AF, Boettner F, Wright J. Does Surgical Approach Affect Outcomes in Total Hip Arthroplasty Through 90 Days of 
Follow-Up? A Systematic Review With Meta-Analysis. J

Arthroplasty. 2018;33(4):1296-1302.

15. Wang Z, Hou JZ, Wu CH, Zhou YJ, Gu XM, Wang HH, Feng W, Cheng YX, Sheng X, Bao HW. A systematic review and meta-analysis of direct anterior approach versus posterior approach in total hip arthroplasty. J Orthop Surg Res. 2018;13(1):229.

16. Jia F, Guo B, Xu F, Hou Y, Tang X, Huang L. A comparison of clinical, radiographic and surgical outcomes of total hip arthroplasty between direct anterior and posterior approaches: a systematic review and meta-analysis. Hip Int. 2018:1120700018820652.

17. Hoskins W, Bingham R, Lorimer M, Hatton A, de Steiger RN. Early rate of revision of total hip arthroplasty related to surgical approach: an analysis of 122,345 primary total hip replacements. J Bone Joint Surg. 2020 (in press).

18. Barnett SL, Peters DJ, Hamilton WG, Ziran NM, Gorab RS, Matta JM. Is the Anterior Approach Safe? Early Complication Rate Associated With 5090 Consecutive Primary Total Hip Arthroplasty Procedures Performed Using the Anterior Approach.J Arthroplasty. 2016;31(10):2291-4.

19. Berend KR, Kavolus JJ, Morris MJ, Lombardi AV Jr. Primary and revision anterior supine total hip arthroplasty: an analysis of complications and reoperations. Instr Course Lect. 2013;62:251-63.

20. Matta JM, Shahrdrar C, Ferguson T. Single-incision anterior approach for total hip arthroplasty on an orthopaedic table. Clin Ortho Rel Research. 2005 Clin Orthop Relat Res. 2005;441:115-24.

This article is protected by copyright. All rights reserved. 
21. Jewett BA, Collis DK. High complication rate with anterior total hip arthroplasties on a fracture table. Clin Orthop Relat Res. 2011;469(2):503-7.

22. De Geest T, Vansintjan P, De Loore G. Direct Anteriror Hip arthroplasty: Complications in a series of 300 cases. Acta Orthop Bel 2013;79:166.

23. Lee GC, Marconi D. Complications Following Direct Anterior Hip Procedures: Costs to Both Patients and Surgeons. J Arthroplasty. 2015;30(9 Suppl):98-101.

24. Woolson ST, Pouliot MA, Huddleston JI. Primary total hip arthroplasty using an anterior approach and a fracture table: short-term results from a community hospital. J Arthroplasty. 2009;24(7):999-1005.

25. Meneghini RM, Elston AS, Chen F, Kheur M, Fehring TK, Springer BD. Direct Anterior Approach: Risk factor for early failure of cementless total hip arthroplasty: a multicenter study. J Bone Joint Surg Am. 2017;99:99-105.

26. Zawadsky MW, Paulus MC, Murray PJ, Johansen MA. Early outcome comparison between the direct anterior approach and the mini-incision posterior approach for primary total hip arthroplasty: 150 consecutive cases. J

Arthroplasty. 2014;29(6):1256-60.

27. Cheng TE, Wallis JA, Taylor NF, Holden CT, Marks P, Smith CL, Armstrong MS, Singh PJ. A Prospective Randomized Clinical Trial in Total Hip Arthroplasty Comparing Early Results Between the Direct Anterior Approach and the Posterior Approach. J Arthroplasty. 2017 Mar;32(3):883-890

This article is protected by copyright. All rights reserved. 
28. Kennon RE, Keggi JM, Wetmore RS, Zatorski LE, Huo MH, Keggi KJ. Total Hip arthroplasty though a minimally invasive anterior surgical approach. J Bone Joint Surg Am. 2003;85-A Suppl 4:39-48.

29. Tripuraneni KR, Munson NR, Archibeck MJ, Carothers JT. Acetabular abduction and dislocations in direct anterior vs posterior total hip arthroplasty: a retrospective, matched cohort study. J Arthroplasty. 2016;31(10):2299-302.

30. Hartford JM, Knowles SB. Risk Factors for Perioperative Femoral Fractures: Cementless Femoral Implants and the Direct Anterior Approach Using a Fracture Table. J Arthroplasty. 2016;31(9):2013-8.

31. Panichkul P, Parks NL, Ho H, Hopper RH Jr, Hamilton WG. New approach and stem increased femoral revision rate in total hip arthroplasty. Orthopedics. 2016;39(1):e8692.

32. Poehling-Monaghan KL, Kamath AF, Taunton MJ, Pagnano MW. Direct anterior versus miniposterior THA with the same advanced perioperative protocols: surprising early clinical results. Clin Orthop Relat Res. 2015;473(2):623-31.

33. Spaans AJ, van den Hout JA, Bolder SB. High complication rate in the early experience of minimally invasive total hip arthroplasty by the direct anterior approach. Acta Orthop. 2012;83(4):342-6.

34. Tay K, Tang A, Fary C. Patten S, Steele R, de Steiger R. The effect of surgical approach on early complications of total hip arthroplasty. Arthroplasty. 2019;1:5.

35. de Steiger RN, Lorimer M, Solomon M. What is the learning curve for the anterior approach for total hip arthroplasty? Clin Orthop Relat Res. 2015;473(12):3860-6.

This article is protected by copyright. All rights reserved. 
36. Janssen L, Wijnands KAP, Janssen D, Janssen MWHE, Morrenhof JW. Do Stem Design and Surgical Approach Influence Early Aseptic Loosening in Cementless THA? Clin Orthop Relat Res. 2018;476(6):1212-1220.

37. Patton RS, Runner RP, Lyons RJ, Bradbury TL. Clinical outcomes of patients with lateral femoral cutaneous nerve injury after direct anterior total hip arthroplasty. J Arthroplasty. 2018;33(9):2919-2926.e1

38. Maratt JD, Gagnier JJ, Butler PD, Hallstrom BR, Urquhart AG, Roberts KC. No Difference in Dislocation Seen in Anterior Vs Posterior Approach Total Hip Arthroplasty. J Arthroplasty. 2016;31(9 Suppl):127-30.

39. Wilson MD, Dowsey MM, Spelman T, Choong PF.

Impact of surgical experience on outcomes in total joint arthroplasties. ANZ J Surg. 2016;86(12):967-972.

Table 1: Patient characteristics according to surgical approach

\begin{tabular}{|c|c|c|c|c|c|c|}
\hline \multirow[b]{2}{*}{ Characteristic } & \multirow[b]{2}{*}{ Category } & \multicolumn{4}{|c|}{ Approach } & \multirow[b]{2}{*}{ p-value } \\
\hline & & $\begin{array}{l}\text { Lateral } \\
(n=1,413)\end{array}$ & $\begin{array}{l}\text { Anterior } \\
(n=233)\end{array}$ & $\begin{array}{l}\text { Posterior } \\
(n=1,188)\end{array}$ & $\begin{array}{c}\text { Superior } \\
(n=72)\end{array}$ & \\
\hline Mean age (SD), $y$ & & $68.7(9.8)$ & $62.6(10.6)$ & $66.4(12.4)$ & $60.1(12.2)$ & $<0.001$ \\
\hline Female sex, $n$ (\%) & & 846 (59.9) & 116 (49.8) & 733 (61.7) & $34(47.2)$ & $<0.001$ \\
\hline \multirow[t]{3}{*}{ BMI (kg), $n(\%)$} & $\begin{array}{l}\text { Underweight } \\
(<18.5)\end{array}$ & $10(0.7)$ & $2(0.9)$ & $11(0.9)$ & $0(0.0)$ & \multirow{3}{*}{0.172} \\
\hline & $\begin{array}{l}\text { Normal (18.5- } \\
24.9)\end{array}$ & 255 (18.1) & $39(16.7)$ & $213(17.9)$ & $5(6.9)$ & \\
\hline & $\begin{array}{l}\text { Overweight } \\
(25-29.9)\end{array}$ & $477(33.8)$ & $74(31.8)$ & $280(32.0)$ & $32(44.4)$ & \\
\hline
\end{tabular}

This article is protected by copyright. All rights reserved. 


\begin{tabular}{|c|c|c|c|c|c|c|}
\hline & $\begin{array}{l}\text { Obese (30- } \\
30.9)\end{array}$ & $565(40.0)$ & $109(46.8)$ & 498 (41.9) & 28 (38.9) & \\
\hline & $\begin{array}{l}\text { Morbidly } \\
\text { obese }(\geq 40)\end{array}$ & $106(7.5)$ & $9(3.9)$ & $86(7.2)$ & $7(9.7)$ & \\
\hline *ASA Score, n (\%) & 1 & $39(2.8)$ & $26(11.2)$ & $53(4.5)$ & $6(8.3)$ & \multirow{4}{*}{$<0.001$} \\
\hline & 2 & 769 (54.4) & $130(55.8)$ & $658(55.4)$ & $39(54.2)$ & \\
\hline & 3 & $578(40.9)$ & $74(31.8)$ & $459(38.6)$ & $26(36.1)$ & \\
\hline & 4 & 27 (1.9) & $3(1.3)$ & $18(1.5)$ & $1(1.4)$ & \\
\hline \multirow[t]{3}{*}{ \#CCl, mean (SD) } & 0 & $834(59.0)$ & $168(72.1)$ & 701 (59.0) & $44(61.1)$ & \multirow[t]{3}{*}{0.005} \\
\hline & 1 & $364(25.8)$ & 37 (15.9) & $327(27.5)$ & $19(26.4)$ & \\
\hline & $2+$ & $215(15.2)$ & $28(12.0)$ & $160(13.5)$ & $9(12.5)$ & \\
\hline \multirow[t]{4}{*}{ Smoking Status, $n(\%)$} & Never & $820(58.0)$ & $137(58.8)$ & 709 (59.7) & $30(41.7)$ & \multirow{4}{*}{0.024} \\
\hline & Ex & 409 (29.0) & $62(26.6)$ & $338(28.5)$ & $24(33.3)$ & \\
\hline & Current & $184(13.0)$ & $34(14.6)$ & $140(11.8)$ & $18(25.0)$ & \\
\hline & Not reported & $0(0.0)$ & $0(0.0)$ & $1(0.1)$ & $0(0.0)$ & \\
\hline \multirow[t]{3}{*}{ Fixation, $n(\%)$} & Uncemented & $169(12.0)$ & $195(83.7)$ & $286(24.1)$ & $66(91.7)$ & \multirow{3}{*}{$<0.001$} \\
\hline & Hybrid & $1222(86.5)$ & 37 (15.9) & $743(62.5)$ & $5(6.9)$ & \\
\hline & $\begin{array}{l}\text { Totally } \\
\text { cemented }\end{array}$ & $22(1.5)$ & $1(0.4)$ & $159(13.4)$ & $1(1.4)$ & \\
\hline \multirow[t]{2}{*}{ Year of Surgery, $n(\%)$} & $2006-2012$ & $1041(73.7)$ & $70(30.0)$ & $777(65.4)$ & $0(0.0)$ & \multirow[t]{2}{*}{$<0.001$} \\
\hline & $2013-2016$ & $372(26.3)$ & $163(70.0)$ & $411(34.6)$ & $72(100.0)$ & \\
\hline
\end{tabular}

*American Society of Anaesthesiologists; \#Charlson Comorbidity Index 
Table 2: Unadjusted and adjusted hazard ratios for complications, by surgical approach

\begin{tabular}{|l|r|r|}
\hline \multicolumn{1}{|c|}{ Approach } & \multicolumn{1}{|c|}{ uHR (95\% CI), p } & \multicolumn{1}{|c|}{ *aHR (95\% CI), p } \\
\hline Lateral (Reference) & 1.0 & 1.0 \\
Anterior & $0.59(0.25,1.37), 0.223$ & $0.63(0.26,1.53), 0.227$ \\
Posterior & $1.11(0.77,1.60), 0.552$ & $0.89(0.57,1.39), 0.610$ \\
Superior & $1.67(0.65,4.26) .0 .286$ & $1.67(0.63,4.43), 0.414$ \\
\hline
\end{tabular}

*Adjusted for year of surgery, BMI (categorical), CCI, fixation and head diameter (categorical) uHR = unadjusted Hazard Ratio aHR $=$ adjusted Hazard Ratio 


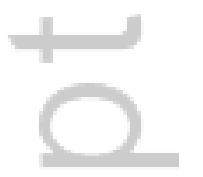


Table 3: Unadjusted and adjusted hazard ratios for complications, by surgical approach

\begin{tabular}{|c|c|c|}
\hline Approach & uHR (95\% CI), p & *aHR (95\% CI), p \\
\hline \multicolumn{3}{|c|}{ Dislocation } \\
\hline Lateral (Reference) & 1.0 & 1.0 \\
\hline Anterior & $1.74(0.36,8.39) 0.490$ & $2.65(0.55,12.81) 0.225$ \\
\hline Posterior & $3.42(1.45,8.09) 0.005$ & $2.90(1.22,6.89) 0.016$ \\
\hline Superior & Insufficient cases & Insufficient cases \\
\hline \multicolumn{3}{|c|}{ *Adjusted for head diameter (categorical) \& aetiology } \\
\hline \multicolumn{3}{|c|}{ Fracture } \\
\hline Lateral (Reference) & 1.0 & 1.0 \\
\hline Anterior & $1.01(0.35,2.90) 0.984$ & $0.50(0.15,1.68) 0.262$ \\
\hline Posterior & $0.79(0.42,1.49) 0.470$ & $0.46(0.22,0.95) 0.037$ \\
\hline Superior & $1.64(0.39,6.91) 0.498$ & $0.36(0.05,2.47) 0.296$ \\
\hline \multicolumn{3}{|c|}{ *Adjusted for sex, fixation \& operative time } \\
\hline \multicolumn{3}{|c|}{$\begin{array}{ll}\text { Infection } \\
\end{array}$} \\
\hline Lateral (Reference) & 1.0 & 1.0 \\
\hline Anterior & Insufficient cases & Insufficient cases \\
\hline Posterior & $0.71(0.40,1.24) 0.223$ & $0.77(0.44,1.37) 0.377$ \\
\hline Superior & $0.62(0.09,4.51) 0.639$ & $0.84(0.11,6.48) 0.866$ \\
\hline \multicolumn{3}{|c|}{ *Adjusted for comorbidity index, year of surgery, BMI (categorical), ASA \& operative time } \\
\hline \multicolumn{3}{|c|}{ Revision } \\
\hline Lateral (Reference) & 1.0 & 1.0 \\
\hline Anterior & $0.96(0.28,3.26) 0.948$ & $1.53(0.43,5.42) 0.511$ \\
\hline Posterior & $1.38(0.75,2.55) 0.302$ & $1.53(0.82,2.83) 0.180$ \\
\hline Superior & $2.09(0.48,8.99) 0.324$ & $3.31(0.71,15.51) 0.068$ \\
\hline
\end{tabular}

This article is protected by copyright. All rights reserved. 


\section{University Library}

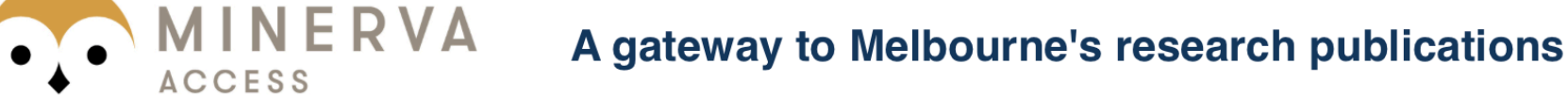

Minerva Access is the Institutional Repository of The University of Melbourne

\section{Author/s:}

Hoskins, W;Dowsey, MM;Spelman, T;Choong, PFM

Title:

Early surgical complications of total hip arthroplasty related to surgical approach

Date:

2020-07-20

Citation:

Hoskins, W., Dowsey, M. M., Spelman, T. \& Choong, P. F. M. (2020). Early surgical complications of total hip arthroplasty related to surgical approach. ANZ JOURNAL OF SURGERY, 90 (10), pp.2050-2055. https://doi.org/10.1111/ans.16149.

Persistent Link:

http://hdl.handle.net/11343/276031 